\title{
Integration of Chemosensory and Hormonal Cues Is Essential for Mating in the Male Syrian Hamster
}

\author{
Ruth I. Wood and Sarah W. Newman \\ Department of Anatomy and Cell Biology, University of Michigan, Ann Arbor, Michigan 48109-0616
}

\begin{abstract}
Mating behavior in the male hamster is dependent upon both chemosensory and hormonal cues, and copulation is abolished if either signal is interrupted. Through reciprocal interactions of these signals, chemosensory stimuli increase circulating testosterone in the male, and the male's hormonal status influences his attraction to female pheromones. Furthermore, anatomical data suggest that these signals are transmitted through parallel pathways in separate subdivisions of the medial amygdaloid nucleus, bed nucleus of the stria terminalis (BNST) and medial preoptic area (MPOA). The aim of this study was to determine if the integration of chemosensory and hormonal cues is essential for mating. We combined an intracerebral implant of testosterone in BNST/MPOA with removal of a single olfactory bulb (UBx), ipsilateral or contralateral to the steroid implant. Previous studies have demonstrated that testosterone implants which stimulate androgen receptor-containing neurons in posteromedial BNST and MPOA can increase mounting in males castrated for 12 weeks. Moreover, unilateral bulbectomy alone does not prevent mating. In the present study, ipsilateral UBx prevents communication between hormonal and chemosensory circuits. Sexually experienced males were used. Twelve weeks after castration, a single olfactory bulb was removed, and each male received a testosterone-filled cannula (23 ga) directed at the MPOA. Two weeks later, sexual activity increased in six males with implants in BNST/MPOA and contralateral UBx, but copulation was not restored in eight males with Ipsilateral UBX desplte equivalent implant placement. This study demonstrates that communication between neurons receiving hormonal signals and chemosensory cues is required for mating behavior.
\end{abstract}

[Key words: brain, male, hamster, animal sex behavior, testosterone, androgen receptor]

Mating behavior in the male hamster is dependent upon chemosensory and hormonal cues, and copulation is abolished if either signal is interrupted (Wood and Newnan, 1995a, for review).

Received May 2, 1995; revised June 26, 1995; accepted July 5, 1995

This work supported by research and training grants (NIH NS-20629, HD07514. HD-32669). We thank Dr. Gail S. Prins of the University of IllinoisChicago for the androgen receptor antiserum, Ms. Carrie Cartwright and Ms. R. Kaye Brabec of the Reproductive Sciences Program Morphology Core Facility (P30-HD-18258) for assistance with tissue processing, and Ms. A. Genene Holt and Mr. David B. Parfitt for their critical evaluation of the manuscript.

Correspondence should be addressed to Ruth I. Wood, Department of Obstetrics and Gynecology, Yale University School of Medicine, 3.3.3 Cedar Street, Box 208063, New Haven, CT 06520-8063.

Copyright $\bigcirc 1995$ Society for Neuroscience $\quad 0270-6474 / 95 / 157261-09 \$ 05.00 / 0$
The present study determined if male hamsters integrate odor and steroid signals during mating, and if such integration is essential for copulation. Chemosensory stimuli are processed through brain regions rich in steroid receptors (Wood and Newman, 1995). However, it is unlikely that substantial numbers of steroid-responsive neurons directly convey chemosensory information. Instead, the distribution of steroid receptor-containing neurons (Krieger et al., 1976; Doherty and Sheridan, 1981; Simerly et al., 1990; Wood et al., 1992; Li et al., 1993; Wood and Newman, 1993a) and the underlying neuronal connections (Gomez and Newman, 1992), suggest that chemosensory and hormonal signals are transmitted through largely separate, but parallel subdivisions within each of three brain regions: the medial amygdaloid nucleus (Me), bed nucleus of the stria terminalis (BNST), and medial preoptic area (MPOA, Fig. 1). According to our hypothesis, synaptic connections between subnuclei of $\mathrm{Me}$, BNST, and MPOA permit reciprocal modulation of neuronal activity along the parallel chemosensory and hormonal circuits. In this manner, gonadal steroid hormones may facilitate transmission of proximate chemosensory cues to brain regions critical for expression of sexual behavior.

Because the male hamster requires both chemosensory cues and steroid hormones to mate, and because these signals are relayed through adjacent brain regions, it has been assumed that chemosensory and hormonal signals are integrated in the brain. This idea is further supported by evidence that the males' attraction to female hamster vaginal secretion (FHVS) is influenced by the internal hormonal milieu (Merkx, 1984; Powers et al., 1985), and that steroid concentrations in circulation increase after exposure to FHVS (Macrides et al., 1974). Although such reciprocal interactions support the concept that chemosensory and hormones cues are indeed coordinated in the brain, it has not previously been determined if this communication is required for sexual activity. As demonstrated in the present study, mating is prevented when communication between chemosensory and hormonal circuits in the brain is blocked.

The approach was to place a single intracerebral implant of testosterone into the BNST/MPOA of castrated male hamsters, and simultaneously remove a single olfactory bulb (UBx), either ipsilateral or contralateral to the steroid implant. This model takes advantage of the predominantly ipsilateral projections of the olfactory system (Davis et al., 1978). Previous studies have demonstrated that unilateral olfactory bulbectomy alone does not impair mating behavior (Murphy and Schneider, 1970; Winans and Powers, 1974), and that testosterone implants in BNST/ MPOA increase mounting in long-term castrates (Lisk and Bezier, 1980; Wood and Newman, 1995b). By combining UBx with unilateral steroid stimulation of the BNST/MPOA, males with 

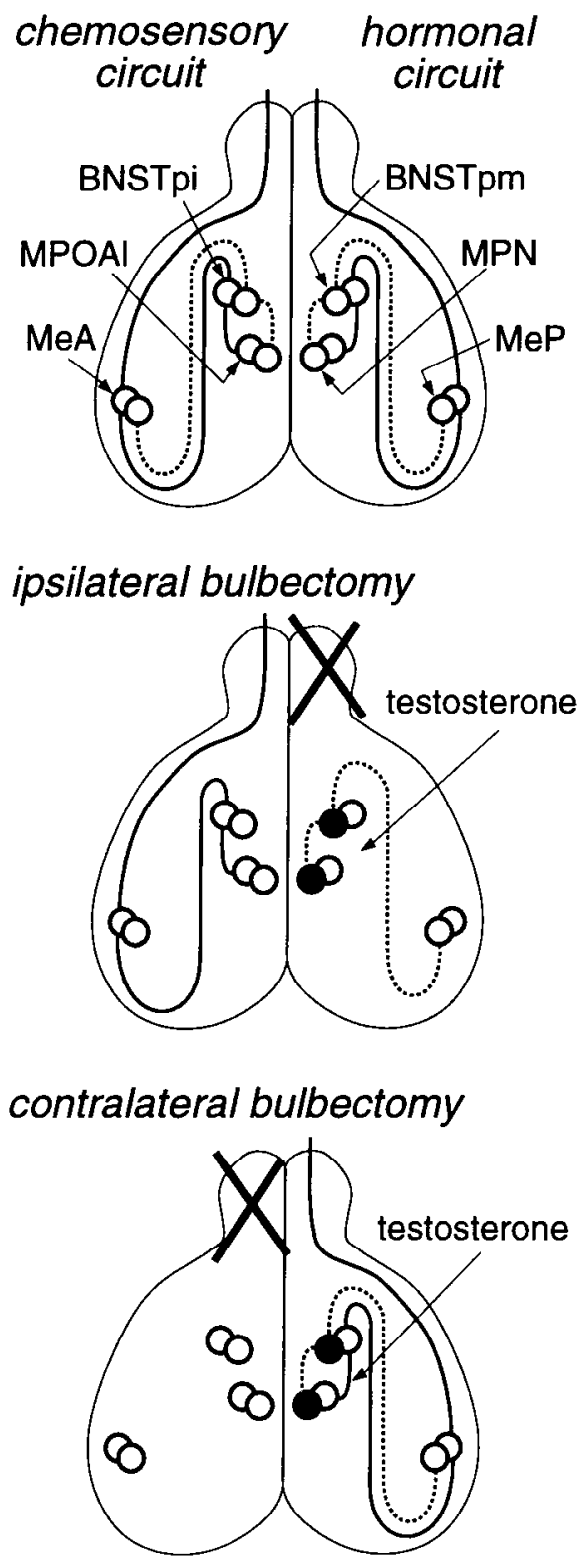

Figure 1. Schematic diagram of mating behavior circuitry through the medial amygdaloid nucleus $(M e)$, bed nucleus of the stria terminalis $(B N S T)$, and medial preoptic area $(M P O A)$ in the male Syrian hamster brain illustrating the separate pathways for receipt of chemosensory and hormonal cues. Top, Normal male. Elements of the chemosensory circuit $(l e f t)$ include the anterior subdivision of $\mathrm{Me}(M e A)$, posterointermediate subdivision of BNST (BNTSpi), and the lateral subdivision of MPOA (MPOAl). The hormonal circuit (right) consists of the posterior subdivision of $\mathrm{Mc}(\mathrm{MeP})$, the postcromcdial subdivision of BNST $(B N S T p m)$, and the medial preoptic nucleus $(M P N)$. Middle, Testosterone stimulation of BNSTpm and MPN (solid circles) combined with removal of the ipsilateral olfactory bulb prevents communication between the chemosensory and hormonal circuits. Bottom, Removal of the contralateral olfactory bulb permits chemosensory and hormonal integration. ipsilateral bulbectomy receive both chemosensory and hormonal signals, but routed through opposite sides of the brain (Fig. 1). If communication between chemosensory and hormonal circuits is required, such males will fail to mate. Males with contralateral UBx should receive and integrate both stimuli through one hemisphere, and engage in mating behavior.

\section{Materials and Methods}

\section{General methods}

Adult male hamsters (Mesocricetus auratus) weighing between 90 and $110 \mathrm{gm}$ were used. Mating tests were conducted during the first four hours of the dark phase under dim light. Each male was placed in a clean Plexiglas cage; 2 min later, a receptive female was introduced. Stimulus females had been previously ovariectomized, and were injected sc with estradiol 17 beta ( $10 \mu \mathrm{g}$ in $0.05 \mathrm{ml}$ sesame oil) 48 and 24 hr beforc usc. To inducc lordosis, each female received 350 ug progesterone $(2.5 \mathrm{mg} / \mathrm{ml}$ in sesame oil) subcutaneously $4 \mathrm{hr}$ before testing. Initially, to provide mating experience for the males and to select subjects for vigorous sexual behavior, all males were exposed on two occasions to a receptive female for $30 \mathrm{~min}$ or until first ejaculation. Throughout the study, at least I week elapsed between mating tests for any individual. Twenty-three males displaying ejaculations on both preliminary mating tests were selected.

To establish baseline measurements of copulatory behavior in the presence of the gonads, sexual activity was recorded with the aid of a Macintosh computer during two 10 min mating tests for each of the 23 sexually experienced males. After the second recorded mating test, males were castrated under sodium pentobarbital anesthesia $(10 \mathrm{mg} / \mathrm{kg})$ via a midline scrotal incision. They received no further treatment for 12 weeks, to allow mating behavior to decline to low levels in the absence of steroids (Morin and Zucker, 1978). Subsequently, mating was recorded again on two occasions to assess copulatory performance of these long-term castrates. Upon completion of postcastration behavior testing, each male was unilaterally bulbectomized and immediately received a single intracerebral implant containing testosterone (see below for implant fabrication and surgery). Beginning 1 week after implant surgery, mating behavior was again recorded on two occasions. at least 1 week apart, for each male. One hour after the final mating test, males were perfused and the brains retained for histology.

\section{Implant fabrication and surgery}

Implant preparation and placement were similar to the methods of Lisk and Bezier (1980). Briefly, stainless steel tubing (23 gauge, Small Parts, Inc.) was sterilized and cut in $2.5 \mathrm{~cm}$ lengths. Crystalline testosterone was dissolved in ethanol, and introduced in one end of the cannula by capillary action. The ethanol evaporates, leaving crystalline steroid behind. The outside of each cannula was cleaned with ethanol and examined under a dissecting microscope to ensure that testosterone filled the end of the implant. To minimize cannula movement after implantation, the extracranial portion of each cannula was bent twice: a $180^{\circ}$ turn $1.5 \mathrm{~cm}$ from the steroid-filled end, and a $90^{\circ}$ turn $0.5 \mathrm{~cm}$ from the distal end.

For implantation, males were anesthetized with pentobarbital $(65 \mathrm{mg} /$ $\mathrm{kg}$ ). The head was shaved, and positioned in a stereotaxic apparatus (David Kopf Instruments, Tujunga, CA), with lambda and bregma in the same horizontal plane. The periosteum and overlying fascial layers were cleared from the skull through a midline incision on the scalp. A single hole was drilled through the skull just large enough to accommodate the steroid-filled cannula. Each male received a single cannula directed towards BNST and MPOA (AP: +1.4, ML: -0.4 , DV: -7.4 relative to bregma). Skull screws (Lomat, Inc., Montreal, Quebec) were placed in each of three surrounding shallow holes. The cannula was lowered to the desired location, and secured to the skull with cranio-

Figure 2. Photomicrographs of androgen receptor immunoreactivity in the medial preoptic nucleus $(M P N)$ and posteromedial subdivision of the bed nucleus of the stria terminalis $(B N S T p m ; A, B)$ and in the posterior subdivision of the medial amygdaloid nucleus $(M e P ; C, D)$ from a castrated male hamster bearing a single intracranial testosterone implant in BNST/POA combined with removal of the contralateral olfactory bulb. Dense immunostaining for androgen receptors in the area surrounding the cannula $(B)$ provides an estimate of testosterone diffusion. Androgen receptor immunoreactivity is faint in other steroid-responsive brain regions, including $\mathrm{MeP}(D)$, and on the opposite side of the brain $(A, B)$. See Materials and Methods for details of androgen receptor staining. Scale bar, $200 \mu \mathrm{m}$. 
A

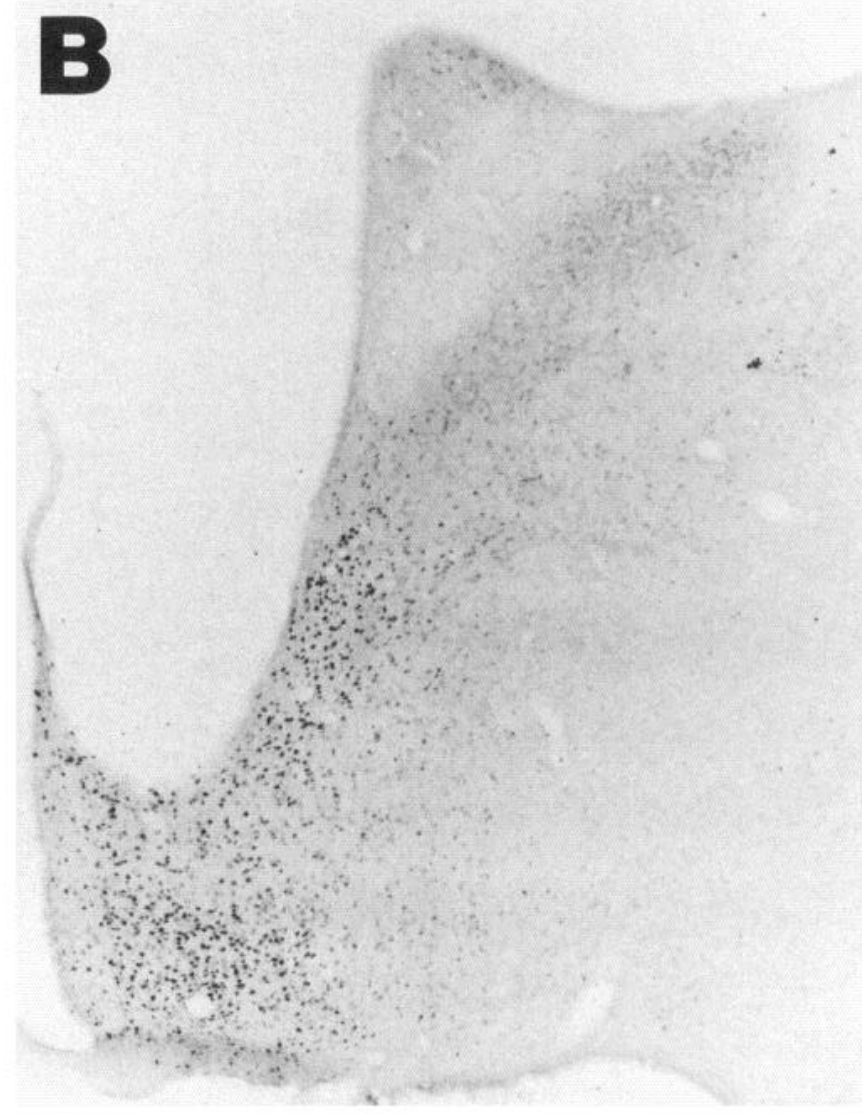

C

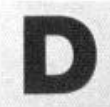

ot

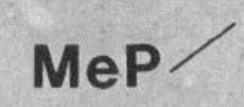

fx

\section{BNSTpm}

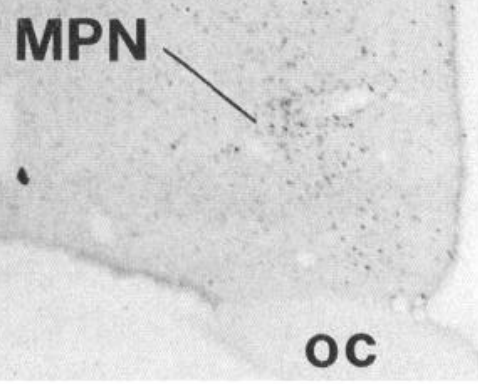

D

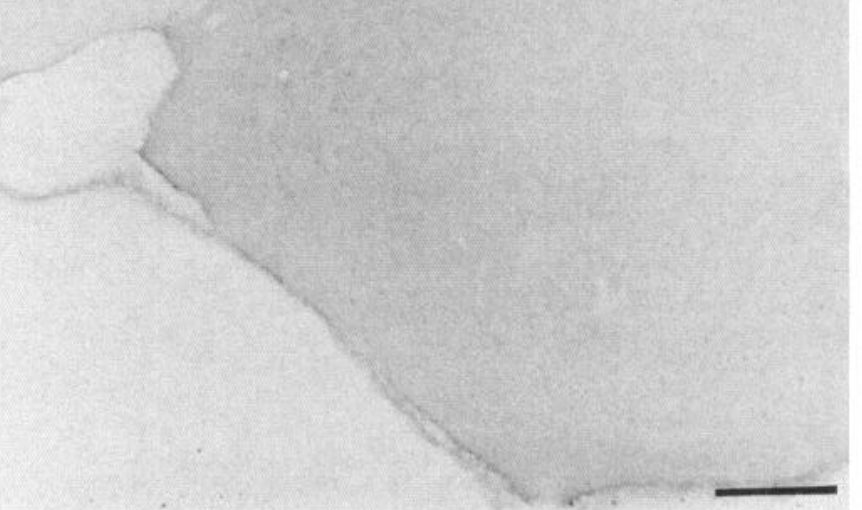


plastic cement (Plastics One, Roanoke, VA). Immediately thereafter, a single olfactory bulb was removed by aspiration through a hole in the overlying bone (Winans and Powers, 1974). The resulting cavity was packed with sterile gel foam. Once the cranioplastic cement had hardened, the skin was sutured over the bent cannula tip and the animal was allowed to recover for 1 week.

\section{Perfusion and histology}

One hour after the second postimplantation mating test, hamsters were deeply anesthetized with sodium pentobarbital $(130 \mathrm{mg} / \mathrm{kg})$, and perfused through the aorta with $150 \mathrm{ml}$ of $0.1 \mathrm{M}$ sodium phosphate-buffered saline containing $0.1 \%$ sodium nitrite for vasodilation, followed by 250 $\mathrm{ml}$ of $0.1 \mathrm{M}$ sodium phosphate buffer (PB) containing $4 \%$ paraformaldehyde. Brains were removed and postfixed in the perfusion fixative for $1 \mathrm{hr}$ at room temperature and then cryoprotected overnight in $\mathrm{PB}$ with $20 \%$ sucrose at $4^{\circ} \mathrm{C}$. Forty micrometer coronal brain sections were cut on a freezing microtome, and collected into $\mathrm{PB}$ with $0.01 \%$ sodium azide as a preservative. Every fourth section was stained with cresyl violet to determine cannula placement. Additional sections were stored at $4^{\circ} \mathrm{C}$ until processed for androgen receptor immunocytochemistry.

Androgen receptor immunocytochemistry. To determine the extent of testosterone efflux from the intracerebral cannula, we profited from the effect of castration on androgen receptor immunoreaclivity. Every fourth section was stained for androgen receptors using the PG-21 antiandrogen receptor antibody $(0.5 \mu \mathrm{g} / \mathrm{ml}$; gift of $\mathrm{G}$. S. Prins $)$. Immunocytochemistry for the androgen receptor followed the protocol reported previously (Wood and Newman, 1993a). In the absence of ligand, immunoreactivity for the androgen receptor is faint or absent when tissues are stained briefly $(5 \mathrm{~min}$ ) in diaminobenzidine (DAB; Wood and Newman, 1993b). In sections from androgen-treated individuals, the same approach is sufficient to reveal dense immunoreactivity over androgen receptor-positive cell nuclei. These changes in immunoreactivity presumably reflect the upregulation of androgen receptor by ligand, as revealed by receptor binding (Krey and McGinnis, 1990; Prins et al., 1990) and Northern blot analysis (Kerr et al., 1993; Robbins et al., 1994). Brief staining of brain sections from males bearing testosteronefilled cannulat reveals numerous androgen receptor-immunoreactive neurons in those brain regions surrounding the testosterone implant, as described previously (Wood and Newman, 1995b). Figure 2 presents photomicrographs of androgen receptor immunoreactivity in Me, BNS'I and MPOA opposite $(A, C)$ and adjacent $(B, D)$ to the testosterone implant. There were no differences in androgen receptor immunostaining from males with ipsilateral or contralateral UBx.

\section{Data analysis}

Cannula placement and bulbectomy. All brains were visually inspected immediately after perfusion to evaluate the completeness of unilateral olfactory bulbectomy. In two males with contralateral UBx and one male with ipsilateral UBx, a rudiment of the olfactory bulb remained. These males werc excluded from the study. With the aid of a drawing tube, the path of the cannula was plotted from sections stained with cresyl violet onto standardized drawings of coronal sections through the hamster brain. The distribution of androgen receptor-immunoreactive neurons from adjacent sections was superimposed on these drawings to determine the extent of testosterone efflux from the steroid-filled cannula. Cannula placement for each male was compared with similar data from our previous study of testosterone stimulation of BNST/MPOA (Wood and Newman, 1995b). Only those males with the potential to respond to the intracerebral implant, as judged by appropriate cannula placement, were included in behavioral analyses.

Behavioral testing. For each mating test, the behavior of the male was recorded each second with the aid of a Macintosh computer. Specific behaviors recorded included no interaction, fighting, grooming, investigation of the femalc, anogenital investigation, cetopic (misoriented) mounting, mounting, intromission, or ejaculation. It is important to note that unilateral intracerebral testosterone implants do not restore copulation to the level of the gonad-intact male. Such implants stimulate only a small subset of steroid-responsive neurons in the brain, and provide no steroidal cues to peripheral structures (i.e., penis and accessory sex glands). Hence, even males with chemosensory and hormonal signals on the same side of the brain (contralateral UBX males) do not show intromissions or ejaculations. From each behavioral record, the total duration of grooming, interaction with the female, anogenital investigation, the number of mounts, and the latency to first mount was calculated. For each individual, data from the two postcastration tests and two postsurgical mating tests was averaged. Mean \pm SEM expression of these behaviors in the two groups was compared by ANOVA, with post-hoc comparisons using the Scheffe $F$ test. In all analyses, $P$ $<0.05$ was considered significant.

\section{Results}

Histology

Figure 3 presents schematic drawings of the path of the intracerebral cannula and the surrounding dense androgen receptor immunoreactivity from a representative males with contralateral UBx (left), and from an ipsilateral UBx male with comparable implant placement (right). In these males, the cannula passed through the medial septum and rostral preoptic area, where lesions do not produce mating deficits. The cannula tip was located in the caudal preoptic area. It was not necessary for the cannula tip to actually contact the target region, as androgen receptor-immunoreactive neurons were visible up to $1 \mathrm{~mm}$ from the end of the cannula. As determined from androgen receptor immunostaining, testosterone preferentially diffuses from the tip of the implant along the cannula path to contact androgen receptor-containing neurons in the medial preoptic nucleus (MPN) and posteromedial BNSI' (BNSIpm). Occasionally, stained neurons were visible rostrally in the ventral lateral septum. Dense androgen rcceptor immunorcactivity typical of intact males (Wood and Newman, 1993a) was not observed in steroid-responsive regions caudally, including the posterior subdivision of Me (MeP; Fig. 2C), ventral premammillary nucleus, arcuate and ventromedial nuclei of the hypothalamus, or on the side of the brain opposite to the hormone implant. The distribution and staining intensity of androgen receptor-containing neurons was similar in contralateral and ipsilateral UBx males with comparable implant placement.

Based on previous experience with intracerebral testosterone implants in BNST/MPOA, sexual behavior is facilitated by testosterone stimulation of steroid receptor-containing neurons extending between BNSTpm and MPN immediately caudal to the anterior commissure (Wood and Newman, 1995b), and equivalent to the males depicted in Figure 3. Of 10 males with contralateral UBx, cannula placement was appropriate to stimulate sexual behavior in 6 males. In the remaining four individuals, the implant was located in the third ventricle $(n=2)$, caudally in the hypothalamus $(n=1)$, or dorsally in the thalamus $(n=1)$. In males with ipsilateral UBx, cannula placement was appropriate in 8 of 10 males. Of the two remaining males with ipsilateral UBx, the cannula was located caudally in the hypothalamus ( $n$ $=1$ ), or laterally in the lateral preoptic area $(n=1)$. No facilitation of behavior was observed in ipsilateral or contralateral UBx males with implants placed outside BNST/MPOA.

\section{Sexual behavior}

Figures 4 and 5 depict mating behavior before orchidectomy, after castration, and after surgery in representative males with contralateral (Fig. 4) and ipsilateral UBx (Fig. 5). Figure 6 presents the mean \pm SEM expression of copulatory and noncopulatory behaviors before and after surgery from contralateral and ipsilateral UBx males with appropriate cannula placement $(n=$ 6 and 8, respectively). Before castration, all males displayed multiple ejaculations during a 10 min test with a receptive female (Figs. 4, 5, top). Twelve weeks later, behavior declined to low levels in all males (Figs. 4-6). These males showed only sporadic interaction with the female, and few mounts were recorded. After surgery, sexual activity was significantly enhanced 


\section{CONTRALATERAL UBX}

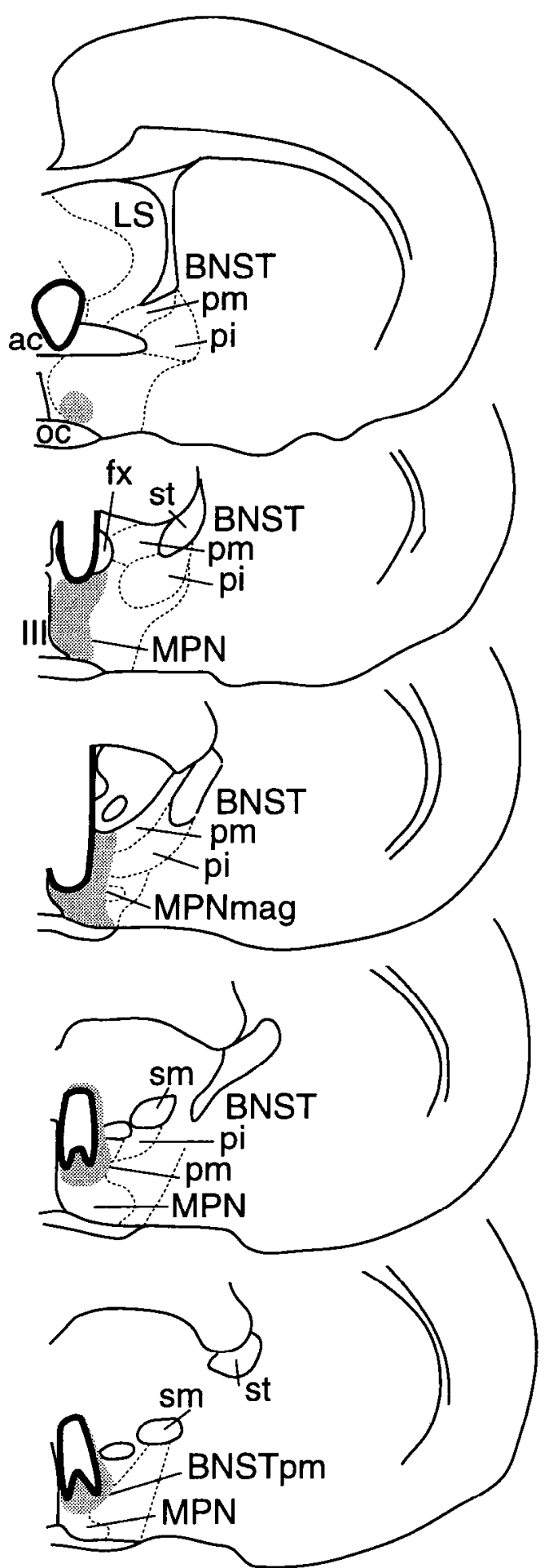

\section{IPSILATERAL UBX}
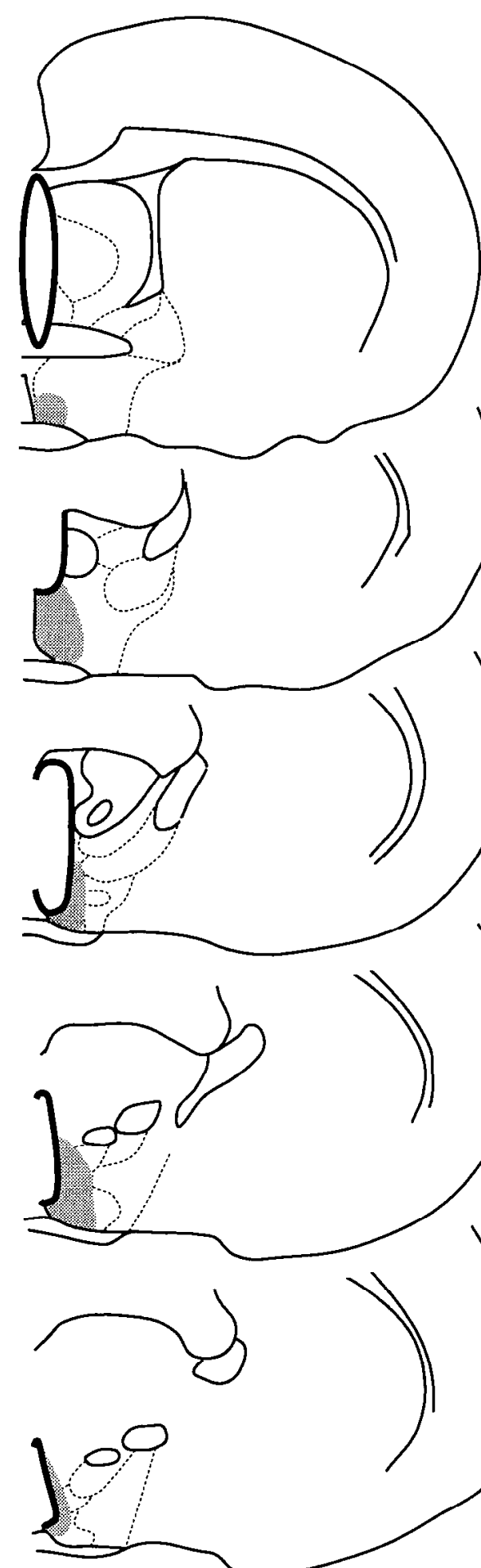

Figure 3. Camera lucida drawings of coronal sections through the brains of two representative castrated adult male hamsters after surgery to place a single intracerebral implant of testosterone in BNST/MPOA and remove a single olfactory bulb contralateral (left) or ipsilateral (right) to the steroid implant. The path of a 23 gauge intracerebral cannula is depicted by the heavy line, androgen receptor immunoreactivity indicative of testosterone binding is illustrated in the shaded area. 
above castrate levels in all 6 contralateral UBx males with appropriate cannula placement (Fig. 6). These effects included an increase in the total interaction with the female (data not shown), grooming, anogenital investigation, number of mounts, and reduced latency to the first mount. Typically, contralateral UBx males displayed bursts of mounting interspersed with grooming or investigation of the female (Fig. 4), as reported previously for bulb-intact males with intracranial steroid stimulation of the preoptic region (Wood and Newman, 1995b).

In males with ipsilateral UBx, expression of sexual activity did not increase following surgery (Figs. 5, 6). The duration of interaction with the female, grooming, and anogenital investigation, as well as the number of mounts and latency to the first mount were not different after testosterone implantation and ipsilateral UBx compared with the behavior of these same individuals as long-term castrates $(P>0.05)$. Moreover, expression of copulatory and noncopulatory behaviors in ipsilateral $\mathrm{UBx}$ males was significantly below that of contralateral UBx males with comparable implant placement $(P<0.05)$.

\section{Discussion}

Previous studies of behavioral responses to odor and hormone signals have suggested that reciprocal communication of these two stimuli occurs. The results of the present study extend those observations to indicate that the interaction of chemosensory and hormonal signals is necessary for mating in the male Syrian hamster. The largely ipsilateral projections of the olfactory bulbs (Davis et al., 1978) made it possible to channel chemosensory and hormonal information through opposite sides of the brain, thereby providing both signals to brain regions that control copulation, but blocking communication between chemosensory and hormonal circuits within these pathways (see Fig. 1). Steroid stimulation of BNST and MPOA has previously been shown to facilitate male sexual behavior after castration (see Sachs and Meisel, 1988). The present study demonstrated that removal of a single olfactory bulb contralateral to the intracranial implant did not compromise testosterone facilitation of sexual activity. However, when males were deprived of chemosensory information ipsilateral to the steroid implant, mating behavior was prevented. This finding opens up the opportunity to explore where and how chemosensory and hormonal cues interact in the brain.

An important framework for describing and distinguishing the separate circuits within Me, BNST, and MPOA that transmit chemosensory and hormonal cues is the concept of the "extended amygdala" (Heimer and Alheid, 1991), parallel rings of interconnected structures in the limbic system which link the corticomedial amygdala with the BNST via the stria terminalis and ventroamygdalofugal pathway. Chemosensory information is transmitted preferentially within a circuit which includes the anterior part of the $\mathrm{Me}(\mathrm{MeA})$ and the posterointermediate division of the BNST (BNSTpi, de Olmos et al., 1985). This circuit is characterized by extensive olfactory and vomeronasal input and by widespread connections to other chemosensory and limbic areas of the forebrain, including connections with the lateral portions of MPOA. Selective bilateral lesions within this circuit which block transmission of chemosensory cues will immediately and permanently abolish mating. Such lesions include deafferentation of the olfactory and vomeronasal inputs to the bulbs (Winans and Powers, 1977), removal of the olfactory bulbs (Murphy and Schnieder, 1970), section of the lateral olfactory tract (Devor, 1973), damage to MeA (Lehman and Win-

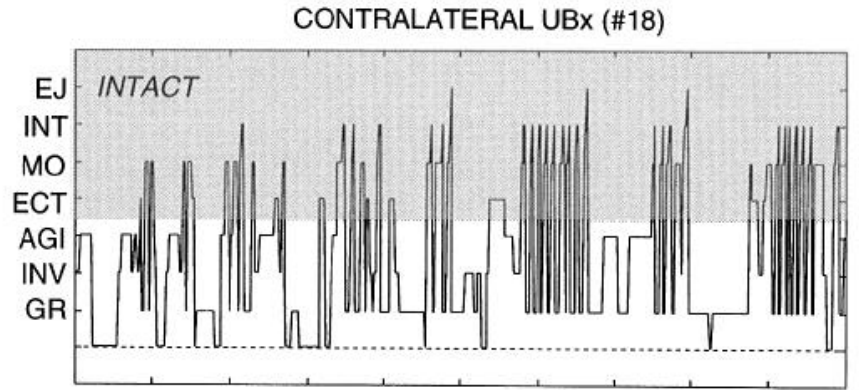

- CASTRATE
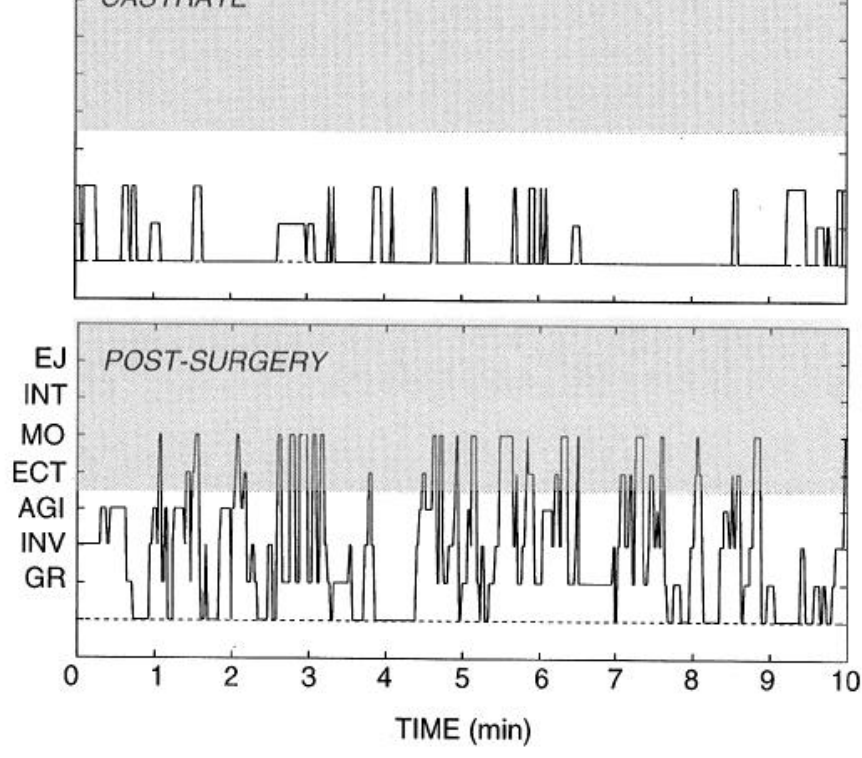

Figure 4. Sexual behavior recorded on three occasions for $10 \mathrm{~min}$ in a sexually experienced male hamster before castration (top), 12 weeks after orchidectomy (middle), and after implantation of a testosteronefilled intracranial cannula in BNST/MPOA and unilateral olfactory bulbectomy contralateral to the steroid implant (bottom). Dotted line indicates no interaction with the receptive female, shaded area indicates mounts, intromissions, and ejaculations. Abbreviations: AGI, anogenital investigation; $E C T$, ectopic mount, $E J$, ejaculation; $G R$, grooming; $I N T$, intromission; $I N V$, investigation of the female; $M O$, mount.

ans, 1982; Lehman et al., 1983), lesions including BNSTpi or centered in the caudal, lateral MPOA (Eskes, 1984; Powers et al., 1987).

A second circuit within the extended amygdala, the network of the posterior $\mathrm{Me}(\mathrm{MeP})$ and posteromedial BNST (BNSTpm), transduces steroid information. Compared to the substantial olfactory and vomeronasal connections through $\mathrm{MeA}$, the subcircuitry through MeP has only limited connections with the accessory olfactory bulbs, and virtually no direct input from the main olfactory bulbs. Further, the projections of this second circuit are restricted to the medial subdivisions of MPOA, including MPN, and the lateral subdivision of VMH (Gomez and Newman, 1992). In contrast to the effects of lesions in the chemosensory circuit, bilateral lesions of MeP, BNSTpm, or MPN, only alter the patterning of mating behavior, but fail to eliminate it (Lehman and Winans, 1982; Powers et al., 1987). However, the majority of hormone-responsive cells are concentrated within this circuit (Krieger et al., 1976, Doherty and Sheridan, 1981; Simerly et al., 1990; Wood et al., 1992; Li et al., 1993; Wood and Newman, 1993a). Fewer steroid receptors are present in the chemosensory subcircuit comprised of MeA, BNSTpi and lateral 

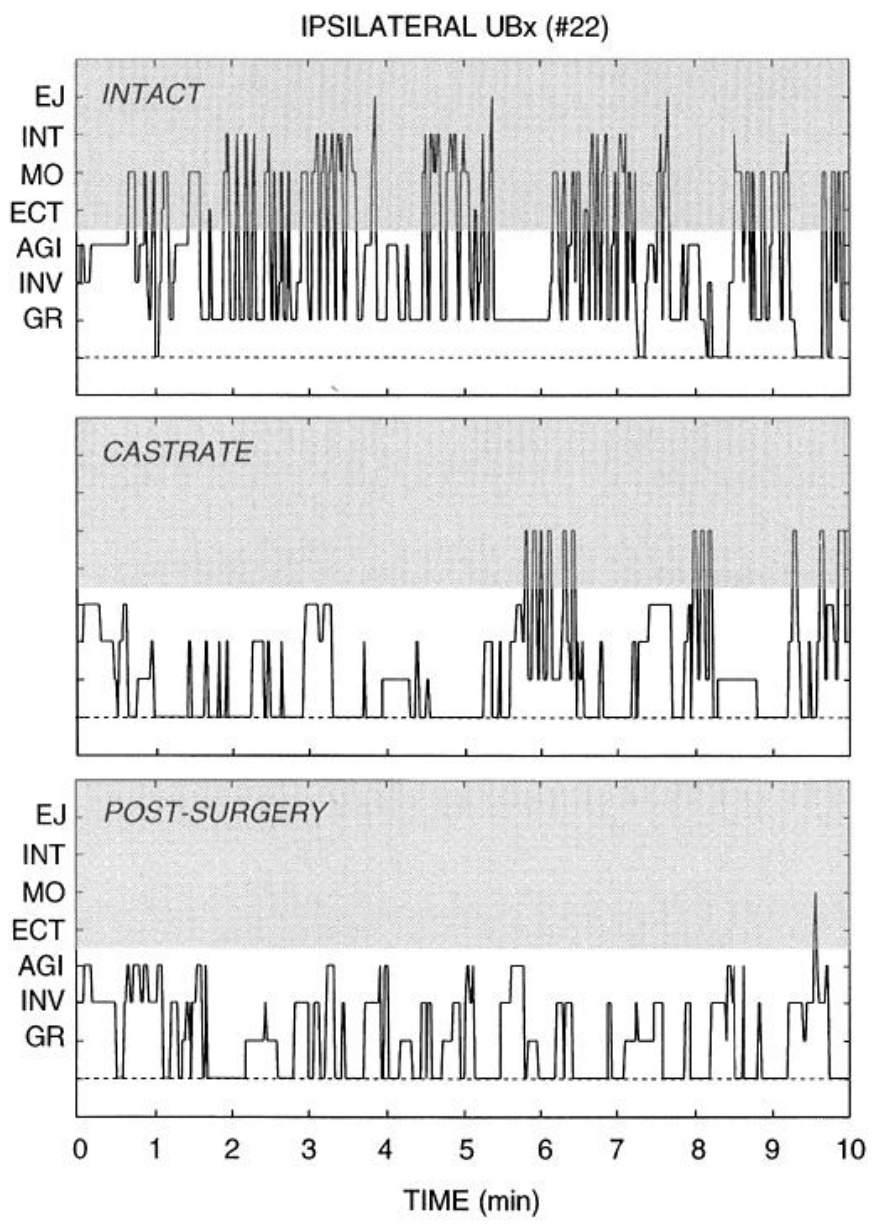

Figure 5. Sexual behavior recorded on three occasions for $10 \mathrm{~min}$ in a sexually experienced male hamster before castration (top), 12 weeks after orchidectomy (middle), and after implantation of a testosteronefilled intracranial cannula in BNST/MOPA and unilateral olfactory bulbectomy ipsilateral to the steroid implant (bottom). Dotted line indicates no interaction with the receptive female, shaded area indicates mounts, intromissions, and ejaculations. Abbreviations: AGI, anogenital investigation; $E C T$, ectopic mount; $E J$, ejaculation; $G R$, grooming; $I N T$, intromission; $I N V$, investigation of the female; $M O$, mount.

MPOA. These observations of the distribution and connections of steroid receptor-containing neurons in hamster limbic system further elaborate on the concept proposed by Cottingham and Pfaff (1986) of a hormone-responsive network in the brain. They reveal that steroid receptors are concentrated preferentially within discrete subnuclei of the larger hormonal circuitry, thereby constituting a hormone-responsive subcircuit of exquisite detail.

The parallel neural circuits for transmission of chemosensory cues through MeA, BNSTpi, and MPOAl and for relay of hormonal signals via MeP, BNSTpm, and MPN provide a model for postulating how and where coordination of sensory and endocrine signals might occur. The results of the present study, together with previous investigations of the functions and connections of discrete subnuclei, provide important insights into potential mechanisms for integration. First, the projections of the olfactory bulbs are predominantly ipsilateral (Davis et al., 1978), and communication between chemosensory and hormonal circuits probably occurs separately and simultaneously on both sides of the brain. Connections between paired subnuclei of $\mathrm{Me}$, BNST, and MPOA through the anterior commissure link the two hemispheres (Maragos et al., 1989; Gomez and Newman, 1992),

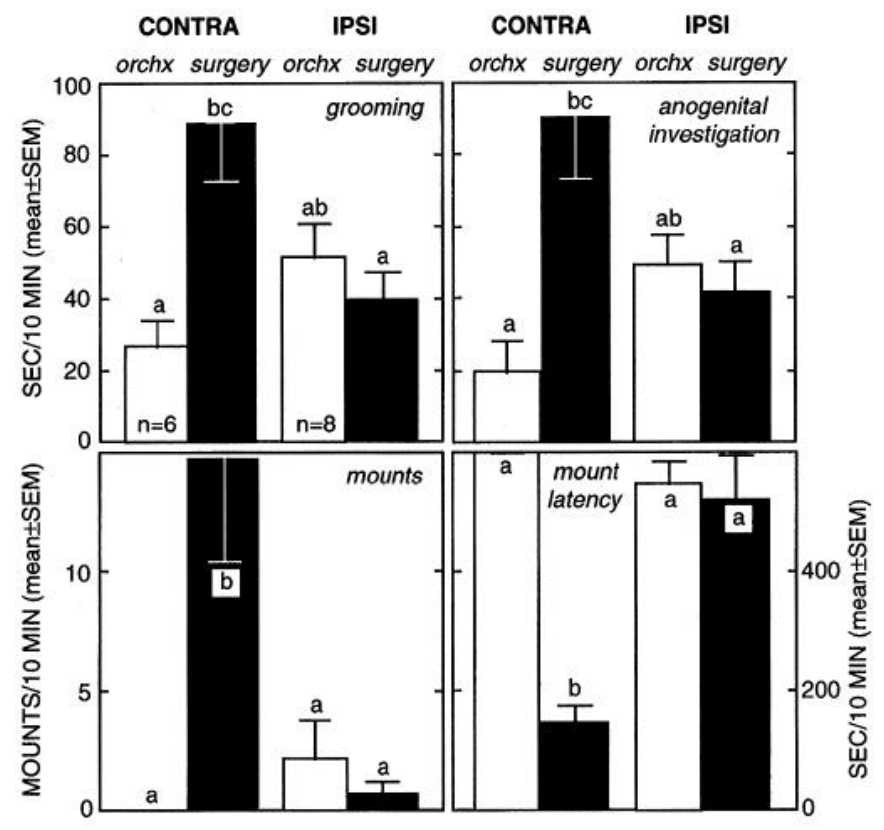

Figure 6. Mean \pm SEM expression of steroid-dependent components of sex behavior in sexually experienced male hamsters during a $10 \mathrm{~min}$ exposure to a receptive female at 12 weeks after castration (open bars, orchx) and after placement of an intracranial testosterone implant in BNST/MPOA and unilateral olfactory bulbectomy (solid bars, surgery). Bulbectomy was performed contralateral (CONTRA) or ipsilateral (IPSI) to the intracranial implant ( $n=6$ and 8 per group, respectively). Bars with common letter superscripts are not significantly different.

and may coordinate mating behavior on both sides of the brain. However, the results of the present study indicate that chemosensory and hormonal stimuli transmitted across the brain through these interhemispheric connections are insufficient to sustain copulatory behavior. Secondly, there exist reciprocal connections linking $\mathrm{MeA}$ and $\mathrm{MeP}$ (Gomez and Newman, 1992). Similar connections may join BNSTpm and BNSTpi and the medial and lateral subdivisions of MPOA as well. Thus, the potential exists for communication between the chemosensory and hormonal circuits via projections of neurons that receive chemosensory cues onto steroid receptor-containing neurons, or vice versa. These connections may be responsible for Fos expression in neurons of MeP and BNSTpm following exposure of the male to female hamster vaginal secretion (Fiber et al., 1993; Fernandez-Fewell and Meredith, 1994). It is not necessary to postulate convergence of these two circuits in a single neuron which receives both chemosensory and hormonal cues. Instead, reciprocal modulation of neuronal activity across synaptic connections between these separate subcircuits may suffice.

Communication between the chemosensory and hormonal circuits is probably not restricted to any single site along the mating behavior pathway, but instead may occur simultaneously across subdivisions of Me, BNST, and MPOA. In the gonad-intact male, gonadal steroids normally bind at multiple sites simultaneously, and each of the principal nuclei along the mating behavior circuit possess large numbers of steroid receptors (Krieger et al., 1976; Doherty and Sheridan, 1981; Simerly et al., 1990; Wood et al., 1992; Li et al., 1993; Wood and Newman, 1993a). An emerging concept of steroid action in the brain is that there is redundancy built into this interconnected network (Cottingham and Pfaff, 1986). In support of this hypothesis, steroid replacement at either Me or BNST/MPOA is sufficient to 
restore normal mating behavior in castrated male hamsters (Lisk and Bezier, 1980; Wood and Newman, 1995b), and rats (Baum et al., 1982; Rasia-Filho, 1991). Conversely, lesions confined to any single element in the hormone-responsive circuitry (MeP, BNSTpm, MPN) fail to prevent the behavior (Lehman et al., 1983; Powers et al., 1987), suggesting that no single site along this pathway is essential for maintenance of sexual activity. Thus, although the present study reveals that the BNST/MPOA area is capable of supporting chemosensory and hormonal integration, this region may not be the sole point of integration. Likewise, it is not possible to define where chemosensory and hormonal integration occurs based only upon the location of the intracerebral cannula. Steroids may indirectly modulate neural activity in areas distant from their binding site, and may also influence the activity of neurons that lack intracellular steroid receptors, as has been demonstrated for the GnRH neurosecretory system (Evans et al., 1994).

Having established the necessity of odor and steroid communication, the challenge is now to understand the cellular nature of the interaction between chemosensory and hormonal circuits. To envision a coherent model for chemosensory and hormonal integration, it must be considered that these two stimuli are transduced by entirely different neuronal mechanisms. Chemosensory cues activate neural impulses along a discrete chain of neurons. The serial arrangement of this network is amenable to study by tract tracing and lesion analysis. Any break in the chain prevents transmission of neural signals generated by chemosensory stimulation, thereby resulting in immediate cessation of the behavior. By contrast, the multiple sites of steroid action and the long-term nature of steroid effects suggest that hormonal stimulation of mating behavior is not achieved solely through direct neuronal excitation, but may include trophic effects on steroid-responsive neurons, as well. Steroid hormones can facilitate branching of neurons (Gomez and Newman, 1991), and formation of synapses (Chung et al., 1988; Nishizuka et al., 1989; Frankfurt and McEwen, 1991; Woolley and McEwen, 1992), effects which tend to promote connectivity. Perhaps projections of steroid-responsive neurons from the hormonal circuit onto neurons of the chemosensory circuit act as a gating mechanism to permit or enhance transmission of chemosensory cues through MeA, BNSTpi, and MPOAl. If so, when steroid hormones are reduced in response to short day photoperiod or eliminated via castration, these facilitatory connections would attenuate. According to this hypothesis, impaired transduction of chemosensory cues in the absence of gonadal steroids would prevent activation of neurons in lateral MPOA in a castrate male following receipt of pheromonal stimuli from a receptive female. The lateral MPOA is critical for expression of copulation, and thus a castrate male would fail to mate. This and other hypotheses can be examined in future years.

\section{References}

Baum MJ, Tobet SA, Starr MS, Bradshaw WG (1982) Implantation of dihydrotestosterone propionate into the lateral septum or medial amygdala facilitates copulation in castrated male rats given estradiol systemically. Horm Behav 16:208-223.

Chung SK, Pfaff DW, Cohen RS (1988) Estrogen-induced alterations in synaptic morphology in the midbrain central gray. Exp Brain Res 69:522-530.

Cottingham SL, Pfaff D (1986) Interconnectedness of steroid hormonebinding neurons: existence and implications. Current topics in neuroendocrinology, Vol 7, pp 223-249. Berlin: Springer.

Davis BJ, Macrides F, Youngs WM, Schneider SP, Rosene DL (1978)
Efferents and centrifugal afferents of the main and accessory olfactory bulbs in the hamster. Brain Res Bull 3:59-72.

de Olmos JS, Alheid GF, Beltramino CA (1985) The amygdala. In: The rat nervous system, Vol 1, Forebrain and midbrain (Paxinos G, ed), pp 223-234. London: Academic.

Devor M (1973) Components of mating dissociated by lateral olfactory tract transections in male hamslers. Brain Res 64:437-441.

Doherty PC, Sheridan PJ (1981) Uptake and retention of androgen in neurons in the brain of the golden hamster. Brain Res 219:327-334.

Eskes GA (1984) Neural control of the daily rhythm of sexual behavior in the male golden hamster. Brain Res 293:127-141.

Evans NP, Dahl GE, Glover BH, Karsch FJ (1994) Central regulation of pulsatile gonadotropin-releasing hormone ( $\mathrm{GnRH}$ ) secretion by estradiol during the period leading up to the preovulatory surge in the ewe. Endocrinology 134:1806-1811.

Fernandez-Fewell G, Meredith M (1994) c-fos expression in vomeronasal pathways of mated or pheromone-stimulated male golden hamsters: contributions from vomeronasal sensory input and expression related to mating performance. J Neurosci 14:3643-3654.

Fiber JM, Adames P, Swann JM (1993) Pheromones induce c-fos in limbic areas regulating male hamster sexual behavior. Neuroreport $4: 871-874$.

Frankfurt M. McEwen BS (1991 Estrogen increases axodendritic synapses in the VMN of rats after ovariectomy. Neuroreport 2:380-382.

Gomez DM, Newman SW (1992) Differential projections of the anterior and posterior regions of the medial amygdaloid nucleus in the Syrian hamster. J Comp Neurol 317:195-218.

Heimer L, Alheid G (1991) Piecing together the puzzle of basal forebrain anatomy. In: The basal forebrain: anatomy to function (Napier TC, Kaliva PW, Hanin I, eds), pp 1-42. New York: Plenum.

Kerr JE, Bollnow MR, Beck SE, Handa RJ (1993) Localization and hormonal regulation of androgen receptor and $\mathrm{c}$-fos gene expression in the rat hippocampus. Soc Neurosci Abstr 327.14.

Krey LC, McGinnis MY (1990) Time courses of the appearance/disappearance of nuclear androgen + receptor complexes in the brain and adenohypophysis following testosterone administration/withdrawal to castrated male rats: relationships with gonadotropin secretion. J Steroid Biochem 35:403-408.

Krieger MS, Morrell JI, Pfaff DW (1976) Autoradiographic localization of estradiol-concentrating cells in the female hamster brain. Neuroendocrinology 22:193-205.

Lehman MN, Winans SS (1982) Vomeronasal and olfactory pathways to the amygdala controlling male hamster sexual behavior. Brain Res 240:27-41.

Lehman MN, Powers JB, Winans SS (198.3) Stria terminalis lesions alter the temporal pattern of copulatory behavior in the male golden hamster. Behav Brain Res 8:109-128.

Lisk RD, Bezier JL (1980) Intrahypothalamic hormone implantation and activation of sexual behavior in the male hamster. Neuroendocrinology 30:220-227.

Macrides F, Bartke A, Fernandez F, D'Angelo W (1974) Effects of exposure to vaginal odor and receptive females on plasma testosterone in the male hamster. Neuroendocrinology 15:35.5-364.

Maragos WF, Newman SW, Lehman MN, Powers JB (1989) Neurons origin and fiber trajectory of amygdalofugal projections to the medial preoptic area in Syrian hamsters. J Comp Neurol 280:59-71.

Merkx J (1984) Effect of castration and subsequent substitution with testosterone, dihydrotestosterone, and oestradiol on sexual preference behaviour in the male rat. Behav Brain Res 11:59-65.

Morin L, Zucker I (1978) Photoperiodic regulation of copulatory behavior in the male hamster. J Endocrinol 77:249-258.

Murphy MR, Schneider GE (1970) Olfactory bulb removal eliminates mating behavior in the male golden hamster. Science 167:302-304.

Nishizuka M, Pfaff DW 1989) Intrinsic synapses in the ventromedial nucleus of the hypothalamus: an ultrastructural study. J Comp Neurol 286:260-268.

Powers JB, Bergondy ML, Matochik JA (1985) Male hamster sociosexual behaviors: effects of testosterone and its metabolites. Physiol Behav 35:607-616.

Powers JB, Newilan SW, Bergondy ML (1987) MPOA and BNST lesions in male Syrian hamsters: differential effects on copulatory and chemoinvestigatory behaviors. Behav Brain Res 23:181-195.

Prins GS, Bartke A, Steger RW (1990) Influence of photoinhibition, photostimulation, and prolactin on pituitary and hypothalamic nuclear 
androgen receptors in the male hamster. Neuroendocrinology 52:511516.

Rasia-Filho AA, Peres TMS, Cubilla-Gutierrez FH, Lucion AB (1991) Effect of estradiol implanted in the corticomedial amygdala on the sexual behavior of castrated male rats. Brazil J Med Biol Res 24: 1041-1049.

Robbins A, Shan L-X, Kumar N, Sundaran K, Hardy MP (1994) Androgen regulates mRNA levels of its receptor in the preoptic area/ hypothalamus of the mouse. Soc Neurosci Abstr 161.4.

Sachs BD, Meisel RL (1988) The physiology of male sexual behavior. In: The physiology of reproduction (Knobil E, Neill JD, eds), pp 1393-1486. New York: Raven.

Simerly RC. Chang C, Muramatsu M, Swanson LW (1990) Distribution of androgen and estrogen receptor mRNA-containing cells in the rat brain: an in situ hybridization study. J Comp Neurol 294:76-95.

Winans SS, Powers JB (1974) Neonatal and two-stage olfactory bulbectomy: effects on male hamster sexual behavior. Behav Biol 10:461471 .

Winans SS, Powers JB (1977) Olfactory and vomeronasal deafferentation of male hamsters: histological and behavioral analyses. Brain Res 126:325-344.
Wood RI, Newman SW (1993a) Mating activates androgen receptor containing neurons in chemosensory pathways of the Syrian hamster brain. Brain Res 614:65-77.

Wood RI, Newman SW (1993b) Intracellular partitioning of androgen receptor immunoreactivity in the brain of the male Syrian hamster: effects of castration and steroid replacement. J Neurobiol 24:925938.

Wood RI, Newman SW (1995a) Hormonal influence on neurons of the mating behavior pathway in male Syrian hamsters. In: The neurobiological effects of sex steroid hormones (Micevych P, Hammer RP, eds), pp 3-39. Cambridge: Cambridge UP.

Wood RI, Newman SW (1995b) The medial amygdaloid nucleus and medial preoptic area mediate steroidal control of sexual behavior in the male Syrian hamster. Horm Behav, in press.

Wood RI, Brabec RK, Swann JM, Newman SW (1992) Androgen and estrogen-concentrating neurons in olfactory and vomeronasal pathways of the male Syrian hamster. Brain Res 596:89-98.

Woolley CS, McEwen BS (1992) Estradiol mediates fluctuation in hippocampal synapse density during the estrous cycle in the adult rat. $\mathrm{J}$ Neurosci 12:2549-2554. 